\title{
Academic stress among high school children
}

\author{
Anupama K ${ }^{1, *}$, Sarada D. ${ }^{2}$ \\ ${ }^{\mathbf{1}}$ Assistant Professor, Dept. of Psychiatry, Kamineni Institute of Medical Sciences, Narketpalli, Telangana, ${ }^{2}$ Professor, Dept. of \\ Home Sciences, Sri Padmavati Mahila Visvavidyalayam, Tirupati, Andhra Pradesh, India
}

*Corresponding Author:

Email: anu_ug@yahoo.co.in

\begin{abstract}
Stress is a state of mental or emotional strain or tension caused by the acts of others, situations and tasks which demand a performance beyond a person's capability or capacity. The children are compelled to spend more hours in schools on all six days a week in Andhra Pradesh, some private schools conduct special classes on Sundays and public holidays. The long hours of schooling, with less scope for; play, sports, recreation, socialization, hobbies and travel, is causing more stress among school children. This study was an exploratory research designed to assess the levels of academic stress among the adolescent boys and girls aged between 14 to 15 years and studying 10th class in Tirupati Municipality. The sample consisted of 240 children of which 120 were boys and 120 were girls. The Academic stress scale consisting of fourty items representing five stressor domains namely; Cognitive, Affective, Behavioral, Physical and Social was developed, standardized and administered.

The findings showed that the adolescent girls and boys perceived high (57.9\%) to very high (40\%) levels of academic stress. There was significant difference between boys and girls in their academic stress in cognitive domain at 0.05 level $(\mathrm{t}=2.311 *$ and $\mathrm{p}=0.022)$ and the girls had stress levels $(31.71 \pm 3.67)$ higher than boys $(30.45 \pm 4.70)$ in this domain. The boys and girls also differed significantly in their physical stress at 0.05 level $\left(\mathrm{t}=2.213^{*}\right.$ and $\left.\mathrm{p}=0.028\right)$ and boys had higher levels $(28.23 \pm 4.86)$ of physical stress when compared to the girls $(26.86 \pm 4.76)$. Among the five stressor domains, statistically significant association was found between gender and behavioural domain of academic stress at 0.01 level $(\chi 2=\mathbf{9 . 9 0 3} * *$ and $\mathbf{p = 0 . 0 0 7})$. There was no association found between gender and Cognitive, Affective, Physical and Social domains. The findings of the study indicates the need for intervention programmes for High school children in stress management and also stresses the need to revisit and revamp our examination system to provide a stress free learning environment to promote mental and general health of school children.
\end{abstract}

\section{Introduction}

The education system in India has become more achievement oriented with more focus on marks and grades, making children work for longer hours in schools and homes. Majority of the parents support this system and pressurize their children to perform better and achieve best or better marks or grades. The children are compelled to spend more hours in schools on all six days a week in Andhra Pradesh, some private schools conduct special classes on Sundays and public holidays. The long hours of schooling, with less scope for; play, sports, recreation, socialization, hobbies and travel, is causing more stress among school children. Stress is a state of mental or emotional strain or tension caused by the acts of others, situations and tasks which demand a performance beyond a person's capability or capacity.

Academic stress involves mental distress regarding anticipated academic challenges or failure or even an awareness of the possibility of academic failure. ${ }^{1}$ During the school years, academic stressors may show in any aspect of the child's environment: home, school, neighborhood, or friendship. ${ }^{2,3}$ Kouzma and Kennedy reported that school-related situations - such as tests, grades, studying, self-imposed need to succeed, as well as that induced by others - are the main sources of stress for high school students. ${ }^{4}$ The impact of academic stress is also far-reaching: high levels of academic stress have led to poor outcomes in the areas of exercise, nutrition, substance use, and self-care. ${ }^{5}$ Furthermore academic stress is a risk factor for psychopathology. For example, fourth, fifth and sixthgrade girls who have higher levels of academic stress are more likely to experience feelings of depression. ${ }^{6}$ The education system in India is highly competitive because of a lack of an adequate number of good institutions to accommodate the ever-expanding population of children. Hence children face competition at the entry level of pre-primary education, and thereafter at the end of every year, in the form of examinations that determine their promotion to the next grade. In classrooms teachers attempt to cover all aspects of a vast syllabus, often disregarding the comprehension level of students. ${ }^{7}$

Tenth grade terminates with first board examination - in which the competition with other students expands from the school-level to the state and even the national level. Studies established that chronic and continued exposure to stressful condition leads to emotional, physical and mental disturbance of the students. ${ }^{11,12}$ Persistent stress leads to low self-esteem of students, difficulty in handling situations, sleep disorders, decreased attention and abnormal appetite which eventually effects the academic achievement and personal growth of students. ${ }^{13}$ With this background an effort was made to assess the academic stress among the High school students in Tirupati, Andhra Pradesh, India. 


\section{Methodology}

The study was an exploratory research designed to assess the levels of academic stress among the adolescent boys and girls aged between 14 to 15 years and studying 10th class in Tirupati Municipality, Chittoor District, and Andhra Pradesh. The list of High Schools in Tirupati was obtained from the office of the District Education officer. The study hours, coaching, disciplinary procedures, punishments, Parent Teacher interactions and student support system varies based on the school management, Hence four private (two CBSE and two State Board )and two Government schools (State Board)were selected from the list of schools randomly and the study was conducted from January to February 2015.

Sample selection: From each Private English medium school 20 boys and 20 girls aged between 14 to 15 years were selected and from Government High schools 40 boys and 40girls were selected as they are Single sex schools, thus the sample consisted of 240 children of whom 120 were boys and 120 were girls. The students who were willing to participate with the consent of the parents were included in the study.

Tools for data collection: The Academic stress scale consisting of fourty items representing five stressor domains namely; Cognitive, Affective, Behavioral, Physical and Social was developed( based on Sinha et al.,(2001)'s thirty item Scale for Assessing Academic Stress), standardized and administered to 240 adolescent boys and girls. Each academic stressor domain consisted of eight items, the respondents were asked to rate each item on a five point scale as; Strongly Agree(SA)-5, Agree(A)-4, Do not Know(DK)3, Disagree (DA)-2, Strongly Disagree(SDA)-1. The Chronbach's Alpha test (C A value $=0.74$ ) was used on a sub sample $(n=40)$ for assessing the internal consistency of the Academic stress scale. Using independent sample $t$-test the difference between the academic stress of girls and boys was studied and the association between the stressor domain wise academic stress and gender was also examined.

\section{Results}

Table 1: The overall academic stress among adolescents

\begin{tabular}{|l|l|c|c|c|}
\hline S. No & $\begin{array}{c}\text { Overall } \\
\text { Academic stress }\end{array}$ & Scores & N & $\begin{array}{c}\text { Percentage } \\
(\boldsymbol{\%})\end{array}$ \\
\hline 1 & Low & $41-80$ & 0 & 0 \\
\hline 2 & Medium & $81-120$ & 5 & 2.1 \\
\hline 3 & High & $121-160$ & 139 & 57.9 \\
\hline 4 & Very high & $161-200$ & 96 & 40.0 \\
\hline \multicolumn{2}{|l|}{} & 240 & 100.0 \\
\hline
\end{tabular}

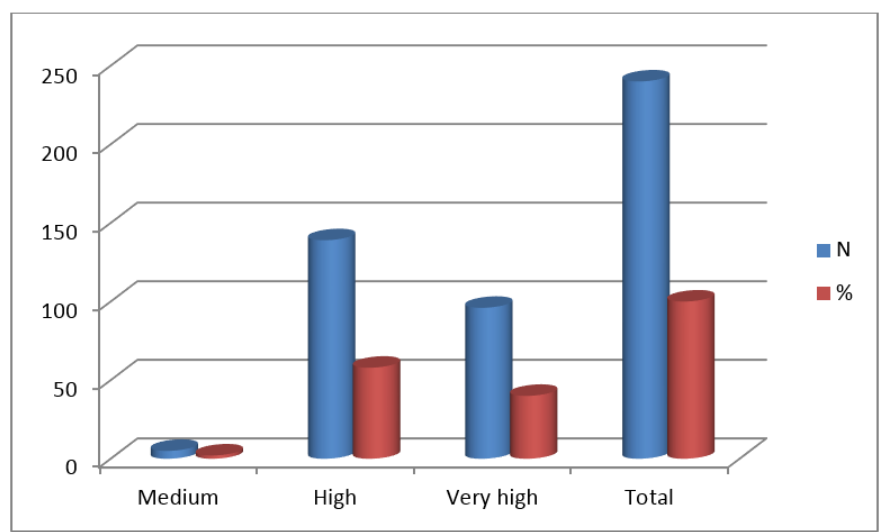

Fig. 1: Academic stress among adolescents

Table 2: Domain wise academic stress scores of adolescents

\begin{tabular}{|c|l|c|c|c|c|c|c|c|c|}
\hline \multirow{2}{*}{ S. No } & \multirow{2}{*}{$\begin{array}{c}\text { Stressor } \\
\text { Domain }\end{array}$} & \multicolumn{2}{|c|}{ Medium } & \multicolumn{2}{c|}{ High } & \multicolumn{2}{c|}{ Very high } & \multicolumn{2}{c|}{ Total } \\
\hline 1 & Cognitive & 3 & 1.3 & 88 & 36.7 & 149 & 62.1 & 240 & 100 \\
\hline 2 & Affective & 1 & 0.4 & 97 & 40.4 & 142 & 59.2 & 240 & 100 \\
\hline 3 & Behavioural & 15 & 6.3 & 159 & 66.3 & 66 & 27.5 & 240 & 100 \\
\hline 4 & Physical & 24 & 10.0 & 143 & 59.6 & 73 & 30.4 & 240 & 100 \\
\hline 5 & Social & 35 & 14.6 & 157 & 65.4 & 48 & 20.0 & 240 & 100 \\
\hline
\end{tabular}


Table 3: Difference between girls and boys with regard to Academic Stress

* Significant at $5 \%$ level

\begin{tabular}{|c|c|c|c|c|c|c|c|}
\hline S. No & $\begin{array}{l}\text { Stressor } \\
\text { Domain }\end{array}$ & Gender & $\mathbf{N}$ & Mean & $\begin{array}{c}\text { Std. } \\
\text { Deviation }\end{array}$ & t-value & p-value \\
\hline \multirow[t]{2}{*}{1} & \multirow[t]{2}{*}{ Cognitive } & Girls & 120 & 31.71 & 3.67 & \multirow[t]{2}{*}{$2.311 *$} & \multirow[t]{2}{*}{0.022} \\
\hline & & Boys & 120 & 30.45 & 4.70 & & \\
\hline \multirow[t]{2}{*}{2} & \multirow[t]{2}{*}{ Affective } & Girls & 120 & 30.46 & 3.04 & \multirow[t]{2}{*}{0.937} & \multirow[t]{2}{*}{0.350} \\
\hline & & Boys & 120 & 30.90 & 4.17 & & \\
\hline \multirow[t]{2}{*}{3} & \multirow[t]{2}{*}{ Behavioural } & Girls & 120 & 27.55 & 3.61 & \multirow[t]{2}{*}{1.362} & \multirow[t]{2}{*}{0.175} \\
\hline & & Boys & 120 & 28.30 & 4.84 & & \\
\hline \multirow[t]{2}{*}{4} & \multirow[t]{2}{*}{ Physical } & Girls & 120 & 26.86 & 4.76 & \multirow[t]{2}{*}{$2.213 *$} & \multirow[t]{2}{*}{0.028} \\
\hline & & Boys & 120 & 28.23 & 4.86 & & \\
\hline \multirow[t]{2}{*}{5} & \multirow[t]{2}{*}{ Social } & Girls & 120 & 26.04 & 4.44 & \multirow[t]{2}{*}{0.583} & \multirow[t]{2}{*}{0.561} \\
\hline & & Boys & 120 & 26.40 & 5.07 & & \\
\hline \multirow[t]{2}{*}{6} & \multirow{2}{*}{$\begin{array}{l}\text { Academic } \\
\text { Stress score }\end{array}$} & Girls & 120 & 142.62 & 16.32 & \multirow[t]{2}{*}{0.670} & \multirow[t]{2}{*}{0.503} \\
\hline & & Boys & 120 & 144.28 & 21.81 & & \\
\hline
\end{tabular}

** Significant at $1 \%$ level

Table 4: The association between the stressor domain wise academic stress and gender

\begin{tabular}{|c|c|c|c|c|c|c|}
\hline S.No & Chi-square & n-value & \multicolumn{3}{|c|}{ Academic stressor domain-cognitive } & \multirow[t]{2}{*}{ Total } \\
\hline \multirow{7}{*}{1} & 5.271 & 0.072 & Medium & High & Very high & \\
\hline & \multirow{4}{*}{ Gender } & Girls & 0 & 39 & 81 & 120 \\
\hline & & & $0.0 \%$ & $32.5 \%$ & $67.5 \%$ & $100.0 \%$ \\
\hline & & Boys & 3 & 49 & 68 & 120 \\
\hline & & & $2.5 \%$ & $40.8 \%$ & $56.7 \%$ & $100.0 \%$ \\
\hline & \multirow{2}{*}{\multicolumn{2}{|c|}{ Total }} & 3 & 88 & 149 & 240 \\
\hline & & & $1.3 \%$ & $36.7 \%$ & $62.1 \%$ & $100.0 \%$ \\
\hline S.No & $\begin{array}{l}\text { Chi-square } \\
\text { value }(\chi 2)\end{array}$ & p-value & \multicolumn{3}{|c|}{ Academic Stressor domain-Affective } & \multirow[t]{2}{*}{ Total } \\
\hline \multirow[t]{7}{*}{2} & 1.038 & 0.595 & Medium & High & Very high & \\
\hline & \multirow{4}{*}{ Gender } & Girls & 0 & 48 & 72 & 120 \\
\hline & & & $0.0 \%$ & $40.0 \%$ & $60.0 \%$ & $100.0 \%$ \\
\hline & & Boys & 1 & 49 & 70 & 120 \\
\hline & & & $.8 \%$ & $40.8 \%$ & $58.3 \%$ & $100.0 \%$ \\
\hline & \multirow{2}{*}{\multicolumn{2}{|c|}{ Total }} & 1 & 97 & 142 & 240 \\
\hline & & & $.4 \%$ & $40.4 \%$ & $59.2 \%$ & $100.0 \%$ \\
\hline S.No & $\begin{array}{l}\text { Chi-square } \\
\text { value }(\chi 2)\end{array}$ & p-value & \multicolumn{3}{|c|}{ Academic stressor domain-Behavioral } & \multirow[t]{2}{*}{ Total } \\
\hline \multirow[t]{7}{*}{3} & $9.903 * *$ & 0.007 & Medium & High & Very high & \\
\hline & \multirow{4}{*}{ Gender } & Girls & 5 & 91 & 24 & 120 \\
\hline & & & $4.2 \%$ & $75.8 \%$ & $20.0 \%$ & $100.0 \%$ \\
\hline & & Boys & 10 & 68 & 42 & 120 \\
\hline & & & $8.3 \%$ & $56.7 \%$ & $35.0 \%$ & $100.0 \%$ \\
\hline & \multirow{2}{*}{\multicolumn{2}{|c|}{ Total }} & 15 & 159 & 66 & 240 \\
\hline & & & $6.3 \%$ & $66.3 \%$ & $27.5 \%$ & $100.0 \%$ \\
\hline S.No & $\begin{array}{l}\text { Chi-square } \\
\text { value }(\chi 2)\end{array}$ & p-value & \multicolumn{3}{|c|}{ Academic stressor domain-Physical } & \multirow[t]{2}{*}{ Total } \\
\hline \multirow[t]{7}{*}{4} & 5.699 & 0.058 & Medium & High & Very high & \\
\hline & \multirow{4}{*}{ Gender } & Girls & 13 & 79 & 28 & 120 \\
\hline & & & $10.8 \%$ & $65.8 \%$ & $23.3 \%$ & $100.0 \%$ \\
\hline & & Boys & 11 & 64 & 45 & 120 \\
\hline & & & $9.2 \%$ & $53.3 \%$ & $37.5 \%$ & $100.0 \%$ \\
\hline & \multirow{2}{*}{\multicolumn{2}{|c|}{ Total }} & 24 & 143 & 73 & 240 \\
\hline & & & $10.0 \%$ & $59.6 \%$ & $30.4 \%$ & $100.0 \%$ \\
\hline S.No & Chi-square & p-value & Acade & essor d & -Social & Total \\
\hline
\end{tabular}




\begin{tabular}{|c|c|c|c|c|c|c|}
\hline & value $(\chi 2$ & & & & & \\
\hline \multirow[t]{7}{*}{5} & 2.361 & 0.307 & Medium & High & Very high & \\
\hline & \multirow{4}{*}{ Gender } & Girls & 16 & 84 & 20 & 120 \\
\hline & & & $13.3 \%$ & $70.0 \%$ & $16.7 \%$ & $100.0 \%$ \\
\hline & & Boys & 19 & 73 & 28 & 120 \\
\hline & & & $15.8 \%$ & $60.8 \%$ & $23.3 \%$ & $100.0 \%$ \\
\hline & \multirow{2}{*}{\multicolumn{2}{|c|}{ Total }} & 35 & 157 & 48 & 240 \\
\hline & & & $14.6 \%$ & $65.4 \%$ & $20.0 \%$ & $100.0 \%$ \\
\hline
\end{tabular}

\section{Discussion}

The study was conducted to assess the levels of academic stress among adolescent girls and boys studying tenth class and to observe the difference between the girls and boys in perception of their academic stress. The findings of the study indicate that the maximum overall academic score is 200 and the minimum score is 40.Based on the overall Academic stress scores the sample were categorized as Low (4180), Medium (81-120), High(121-160) and Very high(161-200).The Table -1 and Figure- 1,shows that majority $(57.9 \%)$ of the adolescents had high academic stress, a 40 percent had very high academic stress, a small percent $(2.1 \%)$ of them had medium stress and none of them had low stress. The domain wise academic stress scores of adolescents showed (see Table 2) that 69.2 percent had very high stress in cognitive domain, a 59.2 percent had very high stress in Affective domain, around 66.3 percent had high stress in Behavioral domain, a 59.6 percent had high stress in Physical Domain and 65.4 percent perceived high social stress. The distribution of sample according to their perceived stress scores indicates that in two domains namely cognitive and affective majority of the adolescents had very high stress, in the three domains; Behavioral, Physical and Social they perceived high stress and a small percent of the sample had medium stress levels in all the five domains .

The difference between the girls and boys with regard to Academic Stress was studied using independent sample t-test. The Table-3 indicates the stressor domain wise difference between the boys and girls in perception of their academic stress. There was significant difference between boys and girls in their academic stress in cognitive domain at 0.05 level $\left(\mathrm{t}=2.311^{*}\right.$ and $\left.\mathrm{p}=0.022\right)$ and the girls had stress levels (31.71 \pm 3.67$)$ higher than boys $(30.45 \pm 4.70)$ in this domain .The cognitive domain of stress encompasses recognition, recollection, comprehension, analysis and synthesis of information and knowledge. If the stress level is high in this domain, it may affect the listening, concentration, memory and other abilities related to cognitive area. The boys and girls understudy also differed significantly in their physical stress at 0.05 level $\left(\mathrm{t}=2.213^{*}\right.$ and $\left.\mathrm{p}=0.028\right)$ and boys had higher levels $(28.23 \pm 4.86)$ of physical stress when compared to the girls $(26.86 \pm 4.76)$. The high levels of physical stress may influence eating and sleeping patterns which in turn may affect the cognitive abilities of a person.
The findings of the study conducted by Nayereh shahmohammadi (2011) showed that: the percentage of distressed secondary students was 26.1percent. The top ten rank of stressors among students were ; afraid of not getting place in tertiary education, examinations, too much content to be learnt, difficulty in understanding subject that have been learnt, too much homework, and school timetable was too packed. All of the stressors were related to the academic matters. While the rest of the top ten stressors were rated as causing moderate to high stress.

The relationship between the stressor domain wise academic stress and gender was examined using Chi square test as shown in Table 4. Among the five stressor domains, statistically significant association was found between gender and Behavioural domain of Academic stress at 0.01 level $(\chi 2=9.903 * *$ and $\mathbf{p}=\mathbf{0 . 0 0 7}$ ). There was no association found between gender and; Cognitive, Affective, Physical and Social domains. The study conducted by Sibnath Deb et al (2015) examined the level of academic stress in $12^{\text {th }}$ class $(10+2$ years) students in Kolkata India. Nearly two-thirds of the students reported stress due to academic pressure - with no significant difference in gender, age, grade, and other personal variables. Around two-thirds of the students reported feeling pressure from their parents for better academic performance. About one-third of the students were symptomatic of psychiatric caseness and 81.6 percent reported examination- related anxiety. Academic stress was positively correlated with parental pressure and psychiatric problems, while examination-related anxiety also was positively related to psychiatric problems. Given the high levels of academic stress and psychiatric caseness in this sample of high school students, there is an urgent need to develop suitable interventions to reduce this level of stress and psychiatric morbidity.

\section{Conclusion}

The results of the study indicate that the adolescent girls and boys aged between 14-15 years and studying $10^{\text {th }}$ class in Private and Government schools perceived academic stress of high (57.9\%)to very high $(40 \%)$ levels . There was significant difference between boys and girls in their academic stress in cognitive domain at 0.05 level $\left(t=2.311^{*}\right.$ and $\left.\mathrm{p}=0.022\right)$ and the girls had stress levels $(31.71 \pm 3.67)$ higher than boys $(30.45 \pm 4.70)$ in this domain. The boys and girls 
understudy also differed significantly in their physical stress at 0.05 level $\left(\mathrm{t}=2.213^{*}\right.$ and $\left.\mathrm{p}=0.028\right)$ and boys had higher levels $(28.23 \pm 4.86)$ of physical stress when compared to the girls $(26.86 \pm 4.76)$. Among the five stressor domains, statistically significant association was found between gender and Behavioural domain of Academic stress at 0.01 level $(\chi 2=9.903 * *$ and $\mathbf{p = 0 . 0 0 7 )}$. There was no association found between gender and Cognitive, Affective, Physical and Social domains. In two domains namely cognitive and affective, majority of the adolescents had very high stress and in the three domains; Behavioral, Physical and Social they perceived high stress. The findings of the study indicates the need for intervention programmes for High school children in stress management and also stresses the need to revisit and revamp our examination system to provide a stress free learning environment to promote mental and general health of school children.

\section{References}

1. Verma S and Gupta J. Some aspects of high academic stress and symptoms. J Personality Clin Studies 1990;6:7-12.

2. Anderson G E, Jimerson S R and Whipple A D. 2005. Student ratings of stressful experiences at home and school: Loss of a parent and grade retention as superlative stressors. J Appl School Psychol 2005;21:1-20.

3. Hess R S and Copeland E P. 2006. Stress. In G. G. Bear \& K. M. Minke (Eds.), Children's needs III: Development, prevention and intervention (pp. 255-265). Washington, DC: National Association of School Psychologists.

4. 4, Kouzma N M and Kennedy G A. Self-reported sources of stress in senior high school students. Psychological Reports 2004;94:314-16.

5. Weidner G, Kohlmann C W, Dotzauer E, and Burns L R. The effects of academic stress on health behaviors in young adults. Anxiety Stress Coping: Int J 1996;9:123-33.

6. Wenz-Gross M and Siperstein G N. Importance of social support in the adjustment of children with learning problems. Exceptional Children 1997;63:183-93.

7. Raina M K. Biochemical consequences of examination stress. Indian Educational Rev 1983;18(2):17-39.

8. Uday K. Sinha, Vibha Sharma, Mahendra K. Development of a scale for assessing academic stress: a preliminary report. J Institute Med 2001;23:105-2.

9. Sibnath Deb, Esben Strodl, Jiandong Sun. Academic Stress, Parental Pressure, Anxiety and Mental Health among Indian High School Students. International Journal of Psychology and Behavioral Sciences. 2015;5(1):26-34.

10. http://soe.syr.edu/academic/counseling_and_human_servi ces/modules/Self_Care/four_dimensions_of_stress.aspx 